\title{
Influence of southern oscillation and SSTs over Nino-3.4 region on the winter monsoon rainfall over coastal Andhra Pradesh
}

\author{
O S R U Bhanu Kumar, C V Naidu and S R L RaO \\ Department of Meteorology and Oceanography, Andhra University, Visakhapatnam, India.
}

\begin{abstract}
An analysis of the mean monthly data of 124 years reveals that the relationship between the Southern Oscillation Index in September and the winter monsoon rainfall (WMR) over Coastal Andhra Pradesh (CAP) is variable and non-stationary. In the recent four decades, however, SOI (Sept) is negatively and significantly correlated with CAP WMR. A similar analysis is performed using 50 years of mean monthly SSTs over Nino-3.4 region in August and September and CAP WMR to detect a possible relationship and there is a striking positive relation between them. In both of the above cases, the September signal is more significant in the recent four decades than for the other months and seasons for probable prediction of CAP WMR. Finally, to examine the influence of $\mathrm{SO}$ on the winter monsoon rainfall, a non-parametric test "Mann-Whitney Rank Statistics" test has been applied to the rainfall associated with extreme positive and negative SOI events.
\end{abstract}

\section{Introduction}

Rainfall during October through December is referred to as winter monsoon rainfall when southwesterlies of summer monsoon are replaced by northeasterlies. It influences prime agricultural activity over five meteorological subdivisions over south India comprising coastal Andhra Pradesh, Rayalaseema, south interior Karnataka, Kerala and Tamilnadu (Srinivasan and Ramamurty 1973; De and Mukhopadhyaya 1999). In the Coromandal coast, Tamilnadu and coastal Andhra Pradesh receive up to $60 \%$ of the total annual rainfall during the winter monsoon. The crop yield in the rabi, which depends on the WMR is more than that of the kharif, particularly in coastal Andhra Pradesh. Thus this rainfall is very important for the above subdivision and it is more crucial when the summer monsoon fails.

There are several studies, which have examined the relation between SOI and Indian summer monsoon rainfall (Sikka 1980; Rasmusson and Carpenter 1983; Shukla and Paolino 1983;
Parthasarathy and Panth 1985; Ropelewski and Halpert 1989 and Mooley 1997). But the relation between them has been weak in the last two decades (Krishna Kumar et al 1999). Studies of the influence of SOI on WMR are, however, meagre. Recent work concludes that the SOI is negatively correlated with WMR in south India (Ropelewski and Halpert 1987; Singh and Chattopadhyaya 1998; Nageswara Rao 1999) and Nino-3.4 SST is positively correlated (Jayanthi and Govindachari 1999). These studies, however, used seasonal values of SOI and Nino-3.4 SST and limited data. But no special attempt is made for coastal Andhra Pradesh.

In this note, we use monthly values of SOI and Nino-3.4 SST instead to show that it is the values for September that are best correlated with WMR over coastal AP.

\section{Data and analysis}

The sources of data sets used in this study are IITM, Pune for WMR (October-December) over

Keywords. Winter monsoon rainfall; southern oscillation; Nino-3.4 SST. 
coastal Andhra Pradesh; Bureau of Meteorology, Australia for SOI and NOAA website for SST over Nino-3.4 region. The period of the data sets of rainfall and SOI is 124 years (1876-1999), while that of SST data is from 1950 to 1999.

The correlation coefficients between the SOI of individual months (January-September) and different seasons and CAP WMR are evaluated. Further, the stationarity of the above relations is tested using 20-year sliding correlation coefficients. The correlation values of $0.38,0.46$ and 0.54 for 20 -year samples are significant at $10 \%, 5 \%$ and $1 \%$ respectively. The Mann and Whitney rank test is applied for the rainfall amounts when the signal is extreme (De and Mukhopadhyaya 1999). Extreme positive and negative events are evaluated based on plus or minus one standard deviation.

Next, the SSTs over Nino-3.4 region in individual months (January-September) and seasons for 50 years are related with the WMR like SOI; it is found that August/September SST in the Nino-3.4 region is related positively and significantly with the WMR. Thus both SOI and SST in September are precursors for the ensuing CAP WMR.

Finally, data relating to the frequency of cyclonic systems over the Bay of Bengal during OctoberDecember crossing the Andhra coast corresponding to the extreme events of September SOI and SSTs are extracted from the cyclonic tracks (India Meteorological Department 1979) and weather reports published by the India Meteorological Department, Pune.

\section{Results and discussion}

The winter monsoon rainfall over coastal Andhra Pradesh is related to the SOI in different months, January through September for the study period and the correlation coefficients are negligible. A 20year sliding window is used to compute the correlations which show that SOI in individual months demonstrates better correlations when compared to seasonal values (table 1). SOI for April from 1970 and May from 1963 and July and August from 1966 onwards maintains significant inverse relation. While the inverse relation between the SOI (September) and rainfall is dominant in the recent four decades (1958 onwards) (figure 1 and table 1). The total correlation between these two parameters for the 4 decades is -0.48 , which is significant at $1 \%$ level.

Table 2 reveals that there are eight years with extreme negative SOI (values less than or equal to mean minus one standard deviation) and another eight years with extreme positive values (values greater than or equal to mean plus one standard deviation). The Mann-Whitney rank test (De and Mukhopadhyaya 1999) is performed for the rainfall associated with the extreme positive and extreme negative SOI episodes during the above 16 years. The test statistic value is 2.1 , which is significant at $5 \%$ level. The inverse relation is clearly seen in 12 years out of 16 years. Coastal Andhra Pradesh received an average amount of $300.9 \mathrm{~mm}$ rainfall (22\% deficit) during positive SOI episodes and an average amount of $494.7 \mathrm{~mm}$ rainfall $(28 \%$ excess) during negative SOI episodes. This indicates a shift towards wetter (drought) conditions in relation to the extreme negative (positive) SOI in September.

The correlations between the Nino-3.4 SSTs for different months January-September and for different seasons showed, in general, a positive tendency with WMR over coastal Andhra Pradesh during 1950-1999. Correlations with 20-year sliding window show that the positive relationship is highly remarkable in the recent four decades (1959 onwards) particularly for September and the correlations in the recent four decades range from 0.37 to 0.66 (figure 2 , table 3 ). The overall correlation coefficient for the recent four decades is 0.39, which is significant at 5\% level. From 1966 onwards the relationship between the August SSTs and rainfall is significant and the correlations vary from 0.49 to 0.71. The SSTs in April, May, June and July have been maintaining significant positive relationships from 1971, 1968, 1968 and 1966 respectively. When compared to the relationships corresponding to different seasons, the relationships with the individual months September and August are more effective. Singh and Chattopadhyay (1998) also related the Nino 3 and 4 SST in different seasons with WMR over Tamilnadu and south Peninsular India. Their correlations are less and range from 0.25 to 0.53. Further, Jayanthi and Govindachari (1999) obtained a correlation of 0.66 between the total Nino-3.4 SST during January through August and WMR over Tamilnadu for the period of 20 years (1978-1997) and reported 10-year lag correlations ranging from 0.3 to 0.8. The September SST positive tendency with the rain in this study is appreciable and will be useful to assess the WMR over coastal Andhra Pradesh.

There are six extreme positive Nino-3.4 SST (September) events (1965, 1972, 1979, 1982, 1987, 1997) and seven extreme negative Nino-3.4 SST events $(1964,1970,1973,1975,1988,1998$ and 1999). The average WMR over coastal Andhra Pradesh in the extreme positive events is $112 \%$ of the long term mean WMR, while that in the extreme negative events is $81 \%$ of mean WMR.

The high rainfall over the Coromandel coast of India is due to equatorial trough and the distur- 
Table 1. 20-year sliding correlations between winter monsoon rainfall over coastal Andhra Pradesh and SOI in different months and seasons.

\begin{tabular}{|c|c|c|c|c|c|c|c|c|c|c|c|c|c|c|}
\hline Year & Dec & Jan & Feb & Mar & Apr & May & Jun & Jul & Aug & Sep & DJF & MAM & JJA & JJAS \\
\hline 1950 & .10 & -.28 & -.14 & -.15 & -.06 & .11 & .10 & .17 & .17 & -.05 & -.14 & -.02 & .16 & 1 \\
\hline 1951 & .09 & -.21 & -.04 & -.15 & .00 & .11 & .11 & .26 & .17 & -.11 & -.07 & .01 & .21 & .12 \\
\hline 1952 & .20 & -.13 & -.04 & -.24 & -.11 & .04 & .13 & .20 & .09 & -.23 & .00 & -.12 & .16 & .05 \\
\hline 1953 & .20 & -.10 & .01 & -.22 & -.17 & -.05 & .02 & .04 & .01 & -.31 & .04 & -.18 & .02 & -.08 \\
\hline 1954 & .19 & -.09 & .01 & -.23 & -.17 & -.11 & .00 & .03 & -.03 & -.34 & .04 & -.22 & .00 & -.10 \\
\hline 1955 & .14 & -.12 & -.03 & -.26 & -.18 & -.12 & -.01 & .01 & -.03 & -.35 & -.01 & -.24 & -.01 & -.11 \\
\hline 1956 & .13 & -.13 & -.03 & -.23 & -.14 & -.12 & .01 & .04 & .01 & -.29 & -.02 & -.21 & .02 & -.08 \\
\hline 1957 & .23 & -.09 & .01 & -.17 & -.21 & -.24 & -.07 & -.14 & -.18 & -.37 & .05 & -.26 & -.15 & -.22 \\
\hline 1958 & .26 & -.07 & .00 & -.20 & -.23 & -.35 & -.12 & -.15 & -.27 & -.45 & .07 & -.31 & -.19 & -.28 \\
\hline 1959 & .35 & .05 & .14 & -.15 & -.19 & -.33 & -.14 & -.20 & -.31 & -.43 & .21 & -.28 & -.24 & -.30 \\
\hline 1960 & .32 & .00 & .09 & -.14 & -.19 & -.32 & -.16 & -.23 & -.36 & -.45 & .16 & -.27 & -.28 & -.33 \\
\hline 1961 & .33 & .00 & .08 & -.13 & -.17 & -.31 & -.18 & -.22 & -.35 & -.43 & .16 & -.25 & -.27 & -.33 \\
\hline 1962 & .34 & -.01 & .10 & -.09 & -.15 & -.33 & -.21 & -.24 & -.36 & -.44 & .17 & -.22 & -.29 & -.34 \\
\hline 1963 & .27 & -.14 & .08 & -.07 & -.17 & -.43 & -.21 & -.23 & -.34 & -.44 & .09 & -.26 & -.28 & -.33 \\
\hline 1964 & .27 & -.08 & .11 & -.03 & -.15 & -.44 & -.19 & -.23 & -.33 & -.44 & .11 & -.23 & -.27 & -.32 \\
\hline 1965 & .22 & -.11 & .08 & .03 & -.09 & -.42 & -.11 & -.21 & -.29 & -.40 & .07 & -.18 & -.22 & -.28 \\
\hline 1966 & .20 & -.14 & .11 & .06 & -.14 & -.46 & -.26 & -.41 & -.39 & -.56 & .06 & -.20 & -.39 & -.45 \\
\hline 1967 & .20 & -.10 & .11 & .10 & -.12 & -.44 & -.25 & -.41 & -.41 & -.56 & .08 & -.16 & -.39 & -.46 \\
\hline 1968 & .02 & -.07 & .07 & .00 & -.32 & -.62 & -.37 & -.50 & -.47 & -.59 & .02 & -.36 & -.48 & -.53 \\
\hline 1969 & .04 & -.05 & .11 & -.03 & -.31 & -.65 & -.31 & -.54 & -.52 & -.65 & .04 & -.37 & -.51 & -.56 \\
\hline 1970 & -.08 & -.02 & .10 & -.11 & -.39 & -.70 & -.40 & -.59 & -.45 & -.61 & .01 & -.46 & -.54 & -.57 \\
\hline 1971 & -.08 & -.09 & .01 & -.13 & -.42 & -.64 & -.35 & -.60 & -.46 & -.60 & -.05 & -.46 & -.52 & -.56 \\
\hline 1972 & .01 & -.06 & .08 & -.07 & -.39 & -.64 & -.35 & -.60 & -.43 & -.60 & .02 & -.45 & -.51 & -.55 \\
\hline 1973 & -.08 & -.16 & .01 & -.17 & -.42 & -.60 & -.34 & -.57 & -.39 & -.55 & -.08 & -.46 & -.48 & -.52 \\
\hline 1974 & -.10 & -.17 & -.01 & -.17 & -.41 & -.59 & -.32 & -.56 & -.38 & -.55 & -.10 & -.45 & -.47 & -.51 \\
\hline 1975 & .02 & -.10 & .08 & -.14 & -.47 & -.62 & -.34 & -.60 & -.44 & -.59 & .00 & -.50 & -.52 & -.56 \\
\hline 1976 & .02 & -.10 & .08 & -.16 & -.51 & -.62 & -.38 & -.70 & -.53 & -.69 & .00 & -.55 & -.62 & -.67 \\
\hline 1977 & -.24 & -.16 & -.01 & -.27 & -.51 & -.65 & -.31 & -.59 & -.43 & -.59 & -.14 & -.61 & -.50 & -.55 \\
\hline 1978 & -.20 & -.15 & .00 & -.27 & -.51 & -.63 & -.32 & -.61 & -.43 & -.58 & -.11 & -.60 & -.50 & -.55 \\
\hline 1979 & -.28 & -.22 & -.15 & -.32 & -.55 & -.58 & -.21 & -.47 & -.33 & -.50 & -.23 & -.61 & -.37 & -.42 \\
\hline 1980 & -.32 & -.26 & -.19 & -.36 & -.56 & -.59 & -.23 & -.48 & -.34 & -.50 & -.27 & -.62 & -.39 & -.43 \\
\hline
\end{tabular}

Dec: December (previous year)

DJF: December (previous year)-January-February

MAM: March-April-May

JJAS: June--July-August-September.

bances in the equatorial trough and the adjoining easterlies (Subbaramayya 1976). They influence the east coast by contributing a lot of precipitation. It is a fact that during ENSO events the cyclonic activity is concentrated in the southern latitudes. The number of Bay of Bengal cyclonic systems crossed along the coastal Andhra Pradesh $\left(14^{\circ}-19^{\circ} \mathrm{N}\right)$ during October-December is shown in 


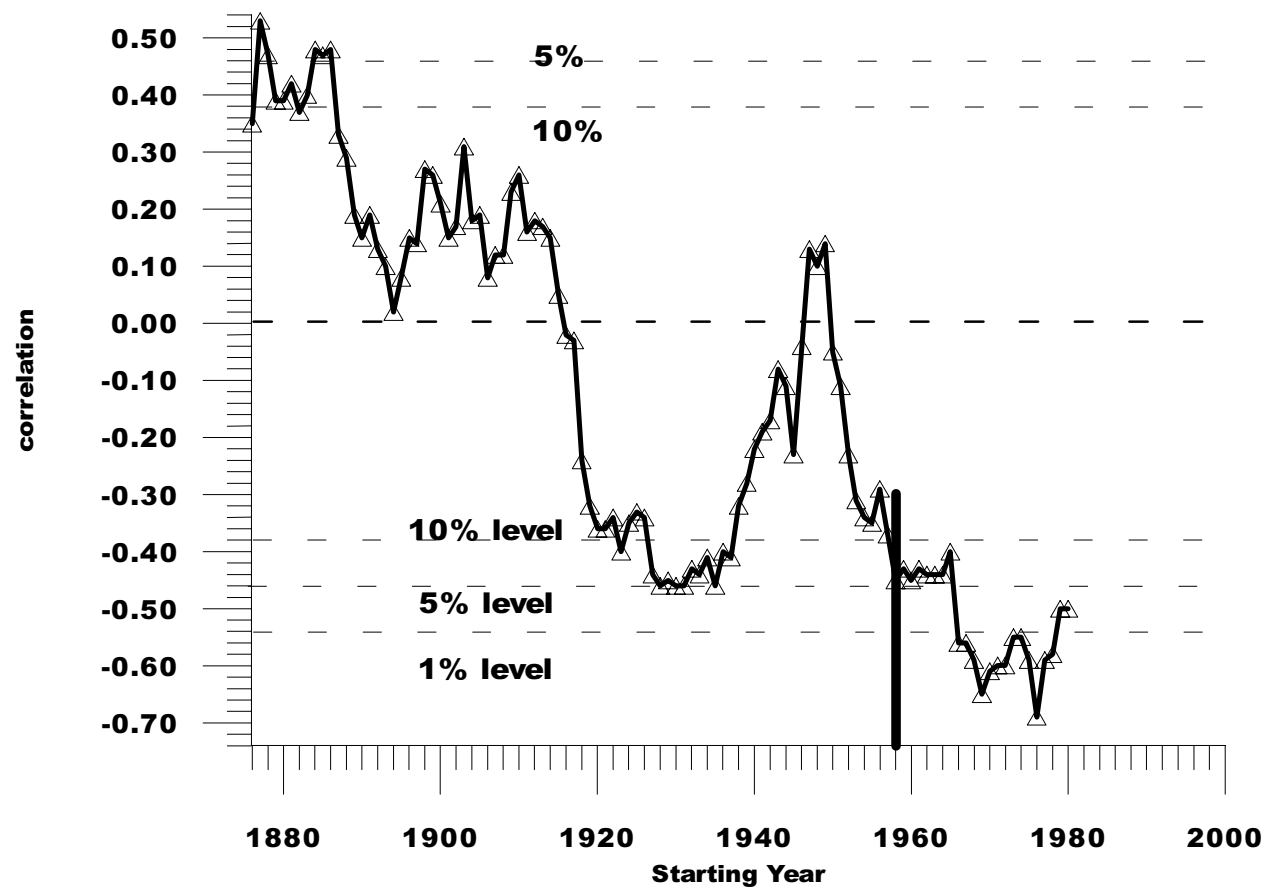

Figure 1. 20-year sliding correlation coefficients between winter monsoon rainfall over coastal Andhra Pradesh and SOI in September.

Table 2. Winter monsoon rainfall amounts over coastal Andhra Pradesh subdivision during extreme negative and positive phases of SOI.

\begin{tabular}{lcc|ccc}
\hline \multicolumn{2}{c|}{ Extreme positive SOI (September) } & \multicolumn{3}{c}{ Extreme negative SOI (September) } \\
\hline Year & $\begin{array}{c}\text { Rainfall } \\
\text { in mm }\end{array}$ & $\begin{array}{c}\text { Normalized } \\
\text { value of SOI }\end{array}$ & Year & $\begin{array}{c}\text { Rainfall } \\
\text { in mm }\end{array}$ & $\begin{array}{c}\text { Normalized } \\
\text { value of SOI }\end{array}$ \\
\hline 1964 & 215.7 & 1.3 & 1965 & 146.8 & -1.3 \\
1970 & 207.0 & 1.2 & 1972 & 539.0 & -1.4 \\
1971 & 239.5 & 1.5 & 1976 & 620.1 & -1.2 \\
1973 & 333.8 & 1.2 & 1982 & 354.0 & -2.0 \\
1974 & 296.8 & 1.1 & 1987 & 663.9 & -1.0 \\
1975 & 420.2 & 2.1 & 1991 & 487.9 & -1.5 \\
1988 & 167.2 & 1.8 & 1994 & 702.7 & -1.6 \\
1998 & 527.3 & 1.0 & 1997 & 443.4 & -1.4 \\
\hline Average $=$ & 300.9 & & Average $=$ & 494.7 & \\
\hline
\end{tabular}

Mean value during 1959 to $1999=385.4 \mathrm{~mm}$

table 4 . The total number of cyclonic systems that crossed the coast in the extreme positive and negative SOI events are 9 and 10 respectively. The severity of the cyclonic systems in the negative SOI events is more, which contributes a lot of precipitation to the coastal Andhra Pradesh.

Most of the extreme negative/positive SST events are the extreme positive/negative SOI events. The number of cyclonic systems that occurred is the same (seven) for all the extreme positive and negative SST events. The intensity of the cyclonic systems is more in the case of positive SST events like negative SOI events.

\section{Conclusions}

Two important points can be drawn from the above study. Monthly SSTs over Nino-3.4 as well as SOI work better when compared to the seasonal indices. These two parameters in September are the key factors for assessing the winter monsoon rainfall over coastal Andhra Pradesh. 
Table 3. 20-year sliding correlations between winter monsoon rainfall over coastal Andhra Pradesh and SSTs (Nino-3.4) in different months and seasons.

\begin{tabular}{|c|c|c|c|c|c|c|c|c|c|c|c|c|c|c|}
\hline Year & Dec & Jan & Feb & Mar & Apr & May & Jun & Jul & Aug & Sep & DJF & MAM & JJA & JJAS \\
\hline 1950 & $* * *$ & .34 & .33 & .41 & .16 & .23 & .16 & -.13 & -.07 & -.09 & $* * *$ & .30 & -.03 & -.05 \\
\hline 1951 & .22 & .28 & .32 & .37 & .10 & .22 & .18 & -.05 & -.01 & -.04 & .28 & .27 & .03 & .01 \\
\hline 1952 & .22 & .26 & .36 & .36 & .18 & .25 & .23 & .02 & .09 & .04 & .28 & .29 & .11 & .09 \\
\hline 1953 & .16 & .21 & .32 & .34 & .22 & .32 & .31 & .13 & .19 & .14 & .23 & .32 & .21 & .19 \\
\hline 1954 & .12 & .18 & .29 & .32 & .25 & .33 & .31 & .14 & .19 & .17 & .19 & .34 & .22 & .21 \\
\hline 1955 & .15 & .21 & .31 & .34 & .26 & .34 & .32 & .15 & .20 & .17 & .22 & .35 & .22 & .21 \\
\hline 1956 & .14 & .22 & .30 & .34 & .25 & .33 & .27 & .12 & .17 & .15 & .21 & .34 & .19 & .18 \\
\hline 1957 & .09 & .12 & .21 & .31 & .22 & .25 & .28 & .20 & .25 & .28 & .13 & .29 & .26 & .27 \\
\hline 1958 & .09 & .12 & .23 & .34 & .29 & .32 & .33 & .28 & .36 & .33 & .14 & .35 & .34 & .34 \\
\hline 1959 & -.02 & -.02 & .11 & .23 & .24 & .28 & .30 & .28 & .35 & .37 & .01 & .28 & .32 & .34 \\
\hline 1960 & .00 & .00 & .15 & .26 & .29 & .33 & .30 & .25 & .34 & .37 & .04 & .32 & .31 & .34 \\
\hline 1961 & .00 & .01 & .14 & .26 & .32 & .34 & .29 & .25 & .35 & .38 & .04 & .34 & .32 & .34 \\
\hline 1962 & -.01 & .02 & .16 & .27 & .33 & .35 & .31 & .27 & .37 & .37 & .04 & .35 & .33 & .35 \\
\hline 1963 & .00 & .04 & .19 & .31 & .37 & .37 & .29 & .26 & .34 & .39 & .06 & .39 & .31 & .34 \\
\hline 1964 & -.03 & .00 & .12 & .20 & .27 & .29 & .26 & .25 & .34 & .39 & .03 & .27 & .30 & .33 \\
\hline 1965 & .05 & .07 & .16 & .21 & .25 & .25 & .24 & .23 & .32 & .35 & .09 & .25 & .28 & .30 \\
\hline 1966 & -.06 & .00 & .11 & .18 & .24 & .30 & .32 & .43 & .54 & .53 & .01 & .25 & .45 & .49 \\
\hline 1967 & -.11 & -.04 & .07 & .13 & .21 & .30 & .31 & .42 & .54 & .54 & -.04 & .22 & .44 & .48 \\
\hline 1968 & -.02 & .06 & .19 & .25 & .31 & .42 & .49 & .57 & .66 & .62 & .07 & .34 & .60 & .61 \\
\hline 1969 & -.09 & .00 & .12 & .21 & .32 & .49 & .57 & .65 & .72 & .66 & .00 & .36 & .67 & .67 \\
\hline 1970 & -.01 & .03 & .11 & .23 & .34 & .44 & .57 & .67 & .70 & .66 & .04 & .35 & .67 & .67 \\
\hline 1971 & .04 & .08 & .16 & .27 & .44 & .48 & .56 & .66 & .69 & .63 & .09 & .41 & .65 & .66 \\
\hline 1972 & -.02 & .04 & .10 & .23 & .41 & .48 & .56 & .67 & .70 & .62 & .04 & .39 & .66 & .66 \\
\hline 1973 & .09 & .13 & .19 & .30 & .42 & .48 & .54 & .65 & .66 & .56 & .13 & .41 & .63 & .62 \\
\hline 1974 & .12 & .16 & .22 & .32 & .41 & .46 & .54 & .65 & .67 & .57 & .17 & .41 & .64 & .63 \\
\hline 1975 & .08 & .10 & .13 & .25 & .37 & .41 & .51 & .60 & .66 & .53 & .10 & .36 & .61 & .60 \\
\hline 1976 & .08 & .10 & .14 & .26 & .38 & .44 & .57 & .65 & .71 & .58 & .11 & .38 & .67 & .66 \\
\hline 1977 & .17 & .22 & .19 & .31 & .47 & .50 & .59 & .66 & .69 & .52 & .20 & .44 & .67 & .65 \\
\hline 1978 & .16 & .20 & .18 & .30 & .47 & .50 & .57 & .60 & .62 & .46 & .18 & .45 & .62 & .59 \\
\hline 1979 & .24 & .29 & .25 & .35 & .47 & .50 & .46 & .46 & .49 & .35 & .26 & .46 & .48 & .46 \\
\hline 1980 & .28 & .33 & .29 & .38 & .49 & .52 & .48 & .49 & .51 & .38 & .30 & .48 & .51 & .48 \\
\hline
\end{tabular}

Dec: December (previous year)

DJF: December (previous year)-January-February

MAM: March-April-May

JJAS: June--July-August-September. 


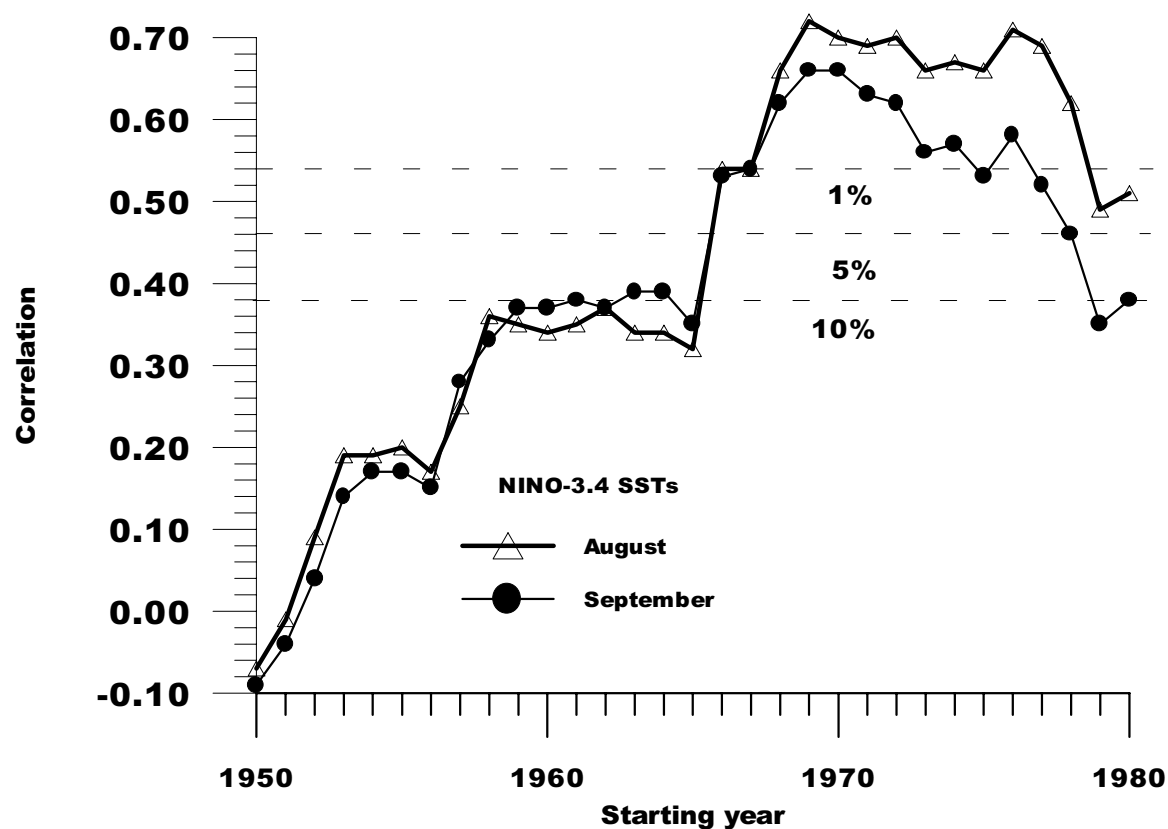

Figure 2. 20-year sliding correlation coefficients between the winter monsoon rainfall over coastal Andhra Pradesh and Nino-3.4 SSTs in August and September.

Table 4. Number of cyclonic systems crossed during October-December in the latitude belt $14^{\circ}-19^{\circ} \mathrm{N}$.

\begin{tabular}{|c|c|c|c|}
\hline \multicolumn{2}{|c|}{$\begin{array}{l}\text { Extreme positive SOI } \\
\text { (September) }\end{array}$} & \multicolumn{2}{|c|}{$\begin{array}{l}\text { Extreme negative SOI } \\
\text { (September) }\end{array}$} \\
\hline Year & $\begin{array}{c}\text { Number of } \\
\text { cyclonic } \\
\text { systems }\end{array}$ & Year & $\begin{array}{l}\text { Number of } \\
\text { cyclonic } \\
\text { systems }\end{array}$ \\
\hline 1964 & $1 d$ & 1965 & Nil \\
\hline 1970 & Nil & 1972 & $1 \mathrm{ss}, 1 \mathrm{~d}$ \\
\hline 1971 & $1 d$ & 1976 & $2 \mathrm{ss}, 1 \mathrm{~s}$ \\
\hline 1973 & Nil & 1982 & $1 \mathrm{~s}$ \\
\hline 1974 & $2 \mathrm{~d}$ & 1987 & $2 \mathrm{ss}, 1 \mathrm{~s}$ \\
\hline 1975 & $1 d$ & 1991 & Nil \\
\hline 1988 & $1 d$ & 1994 & $1 d$ \\
\hline 1998 & $1 \mathrm{ss}, 2 \mathrm{~d}$ & 1997 & Nil \\
\hline \multicolumn{2}{|c|}{ Total $=1 \mathrm{ss}, 8 \mathrm{~d}$} & \multicolumn{2}{|c|}{ Total $=5 \mathrm{ss}, 3 \mathrm{~s}, 2 \mathrm{~d}$} \\
\hline
\end{tabular}

d - depression; s - storm; ss - severe storm.

\section{Acknowledgements}

The authors are thankful to the Department of Science and Technology for their financial support for the research project, 'Studies of winter monsoon over India' (DST No. ESS/63/B2-139/95).

\section{References}

De U S and Mukhopadhyay R K 1999 The effect of ENSO/ Anti ENSO on northeast monsoon rainfall; Mausam 50 4 343-354
India Meteorological Department 1979 Tracks of storms and depressions in the Bay of Bengal and Arabian Sea 1877-1970; India Meteorological Department, New Delhi

Jayanthi N and Govindachari S 1999 El-Nino and northeast monsoon rainfall over Tamilnadu; Mausam 502217

Krishna Kumar K, Rajagopalan B and Cane M A 1999 On the weakening relationship between the Indian monsoon and ENSO; Science 284 2156-2159

Mooley D A 1997 Variation of summer monsoon rainfall over India in El Nino; Mausam 48 413-420

Nageswara Rao G 1999 Variations of the SO relationship with summer and winter monsoon rainfall over India: 1872-1993; J. Climate 12 3486-3495 
Parthasarathy B and Panth G B 1985 Seasonal relationships between Indian summer rainfall and the southern oscillation; J. Climate 5 369-378

Rasmusson E M and Carpenter T H 1983 The relationship between eastern equatorial Pacific Sea surface temperatures and rainfall over India and Sri Lanka; Mon. Weather Rev. 111 517-528

Ropelewski C F and Halpert M S 1987 Global and regional scale precipitation association with El Nino/SO; Mon. Weather Rev. 115 1606-1626

Ropelewski C F and Halpert M S 1989 Precipitation Patterns associated with the high index phase of the Southern Oscillation; J. Climate 2 268-284

Sikka D R 1980 Some aspects of large scale fluctuations of summer monsoon rainfall over India in relation to fluctu- ations in the planetary and regional scale circulation parameters; Proc. Indian Acad. Sci. (Earth Planet Sci.) 89 179-195

Shukla J and Paolino D A 1983 The southern oscillation and long range forecasting of the summer monsoon rainfall over India; Mon. Weather Rev. 111 1830-1837

Singh G P and Chattopadhyaya J 1998 Influence of some circulation anomalies on Indian northeast monsoon; Mausam 494443

Srinivasan V and Ramamurthy K 1973 Comprehensive articles on selected topics, Northeast monsoon; FMU Rep. No. IV 18.4 India Meteorological Department

Subbaramayya I 1976 The northeast monsoon and the causes of the winter rains of southeast India; Meteorol. Mag. 105 153-159 